
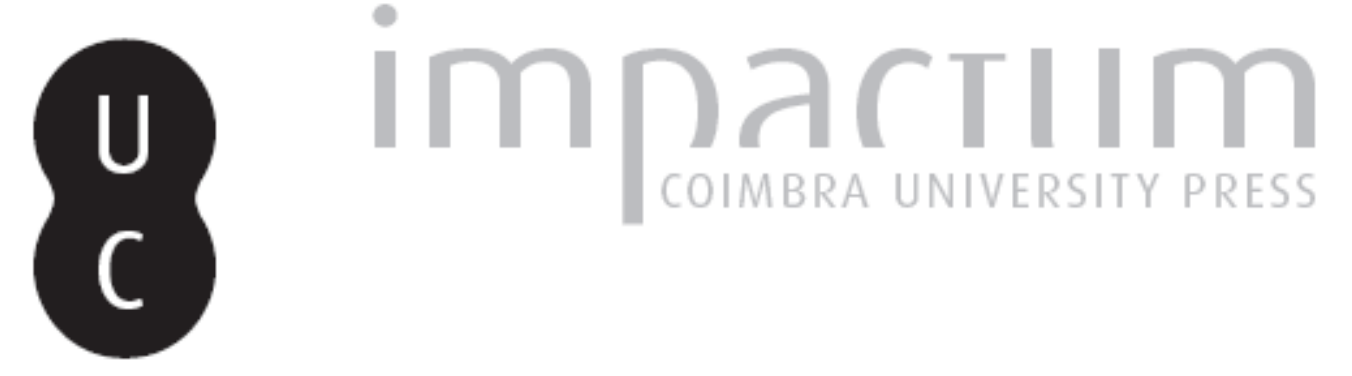

\title{
Desgaste dentário na necrópole medieval de São João de Almedina (séc. XII/XVI) e a sua relação com os hábitos alimentares
}

Autor(es): $\quad$ Carvalho, Liliana Matias de; Wasterlain, Sofia N.

Publicado por: Imprensa da Universidade de Coimbra

URL persistente:

URI:http://hdl.handle.net/10316.2/42127

DOI:

DOI:https://doi.org/10.14195/2182-7982_32_6

Accessed : $\quad$ 26-Apr-2023 01:29:08

A navegação consulta e descarregamento dos títulos inseridos nas Bibliotecas Digitais UC Digitalis, UC Pombalina e UC Impactum, pressupõem a aceitação plena e sem reservas dos Termos e Condições de Uso destas Bibliotecas Digitais, disponíveis em https://digitalis.uc.pt/pt-pt/termos.

Conforme exposto nos referidos Termos e Condições de Uso, o descarregamento de títulos de acesso restrito requer uma licença válida de autorização devendo o utilizador aceder ao(s) documento(s) a partir de um endereço de IP da instituição detentora da supramencionada licença.

Ao utilizador é apenas permitido o descarregamento para uso pessoal, pelo que o emprego do(s) título(s) descarregado(s) para outro fim, designadamente comercial, carece de autorização do respetivo autor ou editor da obra.

Na medida em que todas as obras da UC Digitalis se encontram protegidas pelo Código do Direito de Autor e Direitos Conexos e demais legislação aplicável, toda a cópia, parcial ou total, deste documento, nos casos em que é legalmente admitida, deverá conter ou fazer-se acompanhar por este aviso.

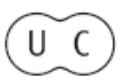




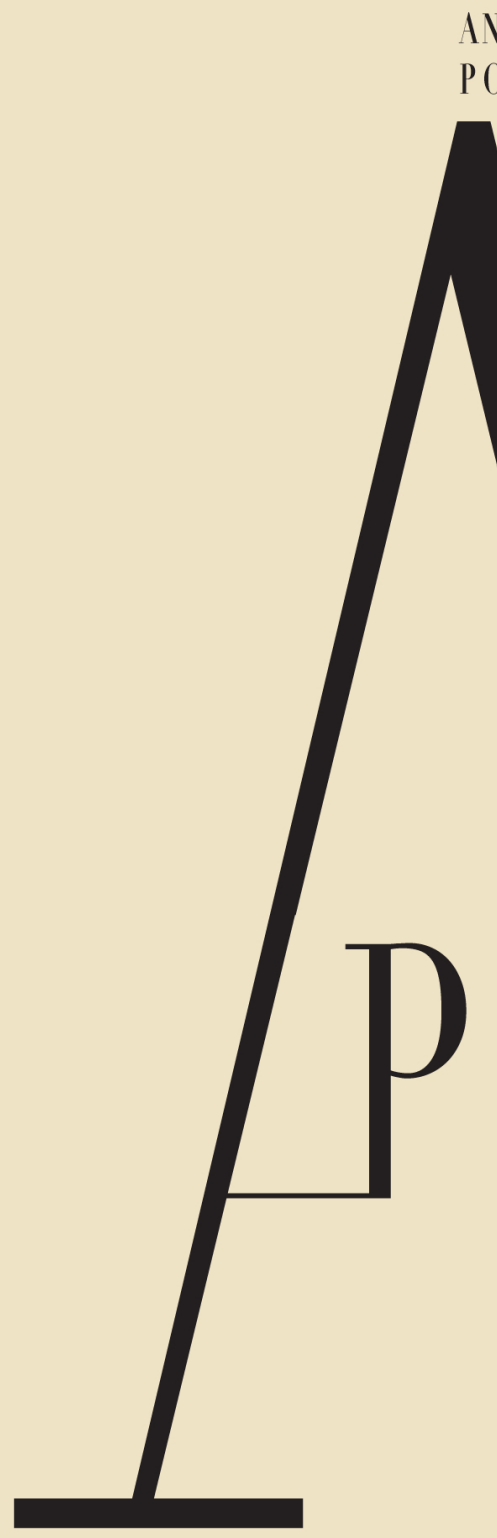

ANTROPOLOGIA

PORTUGUESA 


\section{Desgaste dentário na necrópole medieval de São João de Almedina (séc. XII/XVI) e a sua relação com os hábitos alimentares}

\section{Dental wear in the medieval necropolis of São João de Almedina (12th-16th centuries) and its relationship with eating habits}

\section{Liliana Matias de Carvalho ${ }^{1 *}$, Sofia N. Wasterlain ${ }^{1}$}

Resumo $\bigcirc$ estudo do desgaste dentário em populações arqueológicas é importante para perceber como se vivia no passado, já que, uma vez erupcionados, os dentes não sofrem remodelação. A localização, severidade e tipo de desgaste pode revelar hábitos culturais e dietéticos. O objetivo deste estudo é analisar o padrão de desgaste dentário, por sexo e classe etária, nos indivíduos de uma amostra medieval de São João de Almedina (Coimbra, Portugal) de modo a melhor conhecer os seus hábitos. A amostra em estudo é composta por 58 adultos (28 homens, 20 mulheres e 10 indivíduos de sexo desconhecido).

\begin{abstract}
The analysis of dental wear in archaeological populations is important to understand how past populations lived, given that teeth do not self-remodel after their formation. The location, severity and type of wear may reveal information about cultural habits and diet. This study analyses the dental wear pattern in different sexes and age groups in individuals of a medieval sample from São João de Almedina (Coimbra, Portugal). The sample is composed by 58 adults (28 males, 20 females and 10 individuals of unknown sex). The methodology applied in the recording of theinterproximaland occlusal
\end{abstract}

${ }^{1}$ Centro de Investigação em Antropologia e Saúde, Departamento de Ciências da Vida Universidade de Coimbra, Coimbra, Portugal.

*Corresponding author: liliana.carvalho@student.uc.pt 
Os níveis de desgaste oclusal e aproximal foram registados com os métodos de Smith (1984) e Hillson (2001), respetivamente. Registou-se um desgaste oclusal médio de 3,86 $\pm 1,59$, caraterizado por grande exposição da dentina. Os níveis de desgaste interproximais são baixos $(1,38 \pm 0,72$ e $1,3 \pm 0,75)$. Os resultados foram comparados com outras populações, nomeadamente com os dados de Wasterlain (2006), recolhidos com a mesma metodologia, numa amostra da mesma região geográfica, mas dos finais do século XIX/inícios do século XX. Notou-se uma clara atenuação do desgaste na época pós-industrial, o que pode ser resultado de um menos eficiente processamento da comida em época medieval.

Palavras-chave: Desgaste dentário; dieta; populações do passado; Coimbra.

\section{Introdução}

O desgaste dentário, que implica a perda progressiva de tecido dentário (Wasterlain, 2006), não é considerado uma condição patológica por si só, sendo o resultado do stresse da mastigação ou uso tecnológico (Powell, 1985; Hillson, 1986; Cunha, 1994; Wasterlain, 2006; Silva, 2012), logo uma condição natural que começa depois da erupção dentária (Araújo, 1996).

O estudo do desgaste é importante no conhecimento das populações do passado já que, como o esmalte perdido não é regenerado, fornece informações pós-eruptivas sobre wear rates followed Hillson (2001) and Smith (1984), respectively. The average occlusal wear was $3.86 \pm 1.59$, with a predominant exposure of dentine. The interproximal wear rates were low $(1.38 \pm 0.72$ and $1.3 \pm 0.75)$. The results were compared with data from other populations, namely those referred in Wasterlain (2006), which were collected with the same methodology, in the same geographical region, but from a population that lived in the 19th and early 20th century. A slight decrease in wear was noticeable in the post-industrial age, which may be the result of a less efficient food processing in medieval times.

Keywords:Tooth wear; diet; past populations; Coimbra.

o período funcional dos dentes (Powell, 1985; Wasterlain, 2006; para informações sobre a composição da estrutura do dente, ver Hillson, 1996). Embora provocado por movimentos mecânicos, há também uma grande componente interventiva no desgaste que assenta no tipo de alimentação (Forshaw, 2009; Grmek, 1983 in Cunha, 1994; Marquez-Grant, 2009). Os hábitos culturais dos indivíduos podem ficar também plasmados no desgaste dentário (Araújo, 1996; Molnar, 2011).

Podem-se considerar três tipos de desgaste: a abrasão, o atrito e a erosão (Powell, 1985; Hillson, 1996; Holst e Coughlan, 2000) que se camuflam entre 
si (para mais detalhes, ver Wasterlain, 2006). No entanto, um dente está muito raramente sujeito a uma única forma de desgaste, tendo antes que lidar com uma diversidade de fatores tais como o contacto com outros dentes, a consistência da comida, a erosão ácida, etc. É também conhecida a correlação entre o grau de desgaste e a ordem de erupção dos dentes, o que faz com que os primeiros molares permanentes demonstrem um maior grau de desgaste que os segundos e terceiros. Estes dentes erupcionam com um gradiente de seis anos entre si. Se o gradiente de desgaste for acentuado, isso indica que este será severo (Smith, 1984). É natural que indivíduos que tenham vivido mais anos apresentem maior grau de desgaste já que usaram os seus dentes durante mais tempo (Araújo, 1996).

Tem-se verificado uma diferença nos graus de desgaste consoante a alimentação dos indivíduos (Hillson, 1996). A consistência dos alimentos, dura ou mais macia, pode, de facto, influenciar o próprio processo de mastigação (Grmek, 1983 in Cunha, 1994). O modo como a comida é preparada é também importante (Powel, 1985; Marquez-Grant, 2009) já que partículas da utensilagem podem passar para os alimentos, como por exemplo os elementos pétreos incluídos na farinha quando esta é moída em moinhos, ou nos alimentos triturados com uma mó manual de pedra (Grmek,
1983 in Cunha, 1994; Leek, 1972; MarquezGrant, 2009).

Algumas patologias, como as cáries e a osteoartrose temporomandibular ou mesmo condições como a perda dentária ante mortem, podem ser influentes no grau de desgaste dos dentes (Hodges, 1991). Por outro lado, o desgaste refletese na probabilidade de outras patologias se manifestarem, numa interação que funciona nos dois sentidos (Roberts e Manchester, 2005). Em última instância, o desgaste acelerado, sem dar tempo à produção de dentina secundária, pode expor a câmara polpar do dente, que, desprotegida, pode ser invadida por bactérias que provocarão uma inflamação à volta do ápice da raiz, o que pode levar à perda do dente em vida (Araújo, 1996).

Todos os tipos de desgaste dentário têm uma progressão semelhante, com uma fase inicial em que apenas o esmalte é afetado (grau fisiológico), uma intermédia (grau transitório) em que a dentina secundária está exposta e uma terceira (grau senil) que expõe a cavidade polpar pela penetração de dentina (Klatsky e Klatell, 1943 in Powell, 1985).

O desgaste pode ser também evidência do uso dos dentes como ferramenta ou de modificações dentárias intencionais que afetam sobretudo os dentes anteriores (Wasterlain, 2006; Rufino, 2014). Os hábitos de higiene oral podem influenciar o desgaste, já que, 
por exemplo, há registo do uso de palitos de madeira para limpar os espaços interdentários ou para fins terapêuticos que deixam marcas de abrasão nos dentes (Roberts e Manchester, 2005; Wasterlain, 2006).

Assim, pretende-se analisar o desgaste dentário tendo em atenção o seu grau e padrão, entender de que modo este se exprime em cada sexo e também a forma como evolui com o avanço da idade. Espera-se igualmente que o desgaste forneça informações sobre a dieta e sobre hábitos culturais ou atividades ocupacionais. É fundamental a comparação comamostras populacionais coevas mas também com outras mais antigas ou recentes. Assim, dar-se-á especial atenção aos dados recolhidos por Wasterlain (2006), possuidores de duas vantagens comparativas: foram obtidos com o mesmo método aqui aplicado e referem-se a indivíduos habitantes do mesmo espaço geográfico dos aqui analisados, embora numa época pós-revolução industrial (meados do século XIX a início do século XX).

\section{Material}

O material a considerar neste estudo é proveniente da necrópole da igreja de São João de Almedina (SJA), que se localizava no sítio onde atualmente se encontra o pátio do Museu Nacional de Machado de Castro (MNMC), em Coimbra, e a atual Igreja de São João de Almedina. As escavações neste local sempre estiveram ligadas ao interesse no criptopórtico e fórum romanos que se situam sob o local. Em 1930, Virgílio Correia (in Carvalho, 1998) tornou pública a existência e localização do criptopórtico, iniciando as suas explorações, que decorreram durante toda a década seguinte. Entre 1955 e 1962 decorreu a intervenção da Direcção-Geral dos Edifícios e Monumentos Nacionais (Carvalho, 1998).

No que se refere ao material deste estudo, foi entregue na década de 1940 ao então Instituto de Antropologia da Universidade de Coimbra (Atualmente integrado no Departamento de Ciências da Vida), embora não se tenha conhecimento de nenhum técnico ou investigador ligado ao Instituto que tenha participado na escavação que terá sido dirigida pelo Doutor Bairrão Oleiro (Cunha, 1994). Não se possui qualquer documento escrito sobre a escavação, no entanto, pela análise das fotos, a Doutora Eugénia Cunha pôde inferir que a tipologia das sepulturas se inseria na dos enterramentos da Baixa Idade Média, o que vai ao encontro da cronologia do cemitério. Os enterramentos seriam em decúbito dorsal diretamente na terra, a uma profundidade variável, e podiam ser 
parte de uma sepultura individual ou reutilizada (Cunha, 1994).

A partir de várias fontes e de alguns elementos indiretos, pôde-se balizar com alguma certeza a utilização da antiga Igreja de SJA. Segundo Vasconcelos (1937), citado por Correia e Gonçalves (1947 in Cunha, 1994), esta primeira igreja de SJA terá sido mandada erigir entre 1129 e 1131 e, embora pronta em 1138, apenas foi sagrada no final do séc. XII/inícios do séc. XIII. O claustro, no entanto, terá sido construído num momento anterior, datando de cerca de 1087 (Pimentel, 2005 in Nogueira e Magalhães, 2008). Será menos seguro afirmar o término do seu tempo útil. Coelho (1989) refere que a antiga igreja terá sido abandonada nos finais do séc. XV a favor de uma nova, com a mesma denominação, mas construída não exatamente sobre a antiga (Cunha, 1994). A incerteza da data de encerramento da antiga igreja prende-se com o período de transição para a nova, em que a primeira terá funcionado pontualmente, razão pela qual terá sido referida nos séculos XV e XVI (Cunha, 1994). Deste modo, a igreja original poderia estar ainda a ser utilizada no séc. XVI, já que os registos nos livros paroquiais da nova igreja apenas começam em 1538 (Cunha, 1994). Assim, consegue-se datar o período funcional da antiga igreja de São João de Almedina e respetiva necrópole entre os séculos XII e XVI.

Em 1963, Xavier da Cunha assinou uma publicação onde referia que uma parte do material havia sido alvo de uma análise métrica pela Doutora Maria Augusta Neto (Cunha, 1963). Posteriormente a esta data, os ossos apenas foram estudados em 1994 por Cunha (1994), que procedeu a uma extensa caracterização paleodemográfica e patológica no âmbito da sua dissertação de doutoramento, e por Carvalho (2013), cuja investigação de Mestrado em torno da série se centrou no estudo da patologia dentária.

A amostra analisada é composta por 28 indivíduos masculinos, 20 femininos e 10 de sexo indeterminado, divididos por três classes etárias - adultos jovens, adultos e adultos idosos - num total de 58 (Tabela 1). Apenas foram observados dentes permanentes e in situ. Dos 1084 alvéolos disponíveis, somente 50,3\%

Tabela 1. Distribuição etária e sexual da amostra de São João de Almedina (Coimbra).

\begin{tabular}{llccccc}
\hline & & \multicolumn{4}{c}{ Sexo } \\
& & Indeterminado (n) & Masculino (n) & Feminino (n) & Total \\
\hline \multirow{2}{*}{ Classe } & Adulto Jovem & 2 & 1 & 4 & 7 \\
Etária & Adulto & 10 & 20 & 10 & 40 \\
& Adulto Idoso & 0 & 5 & 6 & 11 \\
\hline \multirow{2}{*}{ Total } & & 12 & 26 & 20 & 58 \\
\hline
\end{tabular}


(546/1084) continham dentes aptos para o estudo do desgaste oclusal.

Para o registo do desgaste oclusal, considera-se mais apropriado o método de Smith (1984) readaptado por Hillson (2001), já que reduz o erro inter e intraobservador. O método de Smith (1984) consiste num diagrama dividido em oito graus de acordo com o padrão de exposição de dentina. Em 2001, Hillson acrescentou a este diagrama um grau 10 para se referir a um dente fraturado que deixe visível uma superfície com algum desgaste. É um método bastante usado atualmente, o que favorece a comparação dos resultados, embora alguns investigadores o considerem pouco discriminatório quando o desgaste é leve (Araújo, 1996). Refirase que também Murphy (1959), Molnar (1971) e Scott (1979), entre outros, desenvolveram métodos de registo de desgaste.

Quanto ao atrito aproximal, utilizouse o método de Hillson (2000, 2001), que propõe o registo do comprimento da faceta de atrito atribuindo uma cotação à sua aparência (Wasterlain, 2006). Um outro método de registo deste tipo de desgaste foi desenvolvido por Wolpoff (1971).
Os dados foram recolhidos numa ficha de registo depois de uma cuidada observação macroscópica, sob uma luz direta de modo a que não existissem zonas obscurecidas, e com o auxílio de lupa. Seguiu-se a inclusão dos registos numa base de dados construída em SPSS versão 17.0, sendo posteriormente alvo de tratamento estatístico (teste de quiquadrado).

\section{Resultados}

\section{Desgaste 0clusal}

Dos 1084 alvéolos disponíveis, apenas 50,3\% (546/1084) continham dentes em condições de ser incluídos no estudo do desgaste oclusal. A média de desgaste é de 3,86 $( \pm 1,59)$, o que corresponde a um desgaste moderado com grandes quantidades de dentina expostas e já com as cúspides removidas. As médias por sexos são de 4,02 $( \pm 1,49)$ para os indivíduos do sexo masculino $(n=331)$ e ligeiramente mais baixa $-3,31( \pm 1,62)$ - para o sexo feminino $(n=154)$. Os indivíduos de sexo indeterminado apresentam uma média de desgaste mais alta do que os de sexo identificado $-4,39( \pm 1,67, n=61)$.

Os graus de desgaste mais representados são os graus $4(25,3 \%$, $n=138)$ e $3(24,7 \%, n=135)$. É interessante 
verificar que o grau 8 - dente com perda severa ou completa da altura da coroa e do anel de esmalte, ficando a superfície da coroa com a forma das raízes é o menos frequente $(1,3 \%, \mathrm{n}=7)$. A expressão de todos os graus observados pode ser visualizada na Figura 1.
Quando se analisam os dados por sexo (Tabela 2), há uma maior frequência do grau 2 (35,7\%, n = 55) no sexo feminino e dos graus $3(27,2 \%$, $n=90)$ e $4(29,6 \%, n=98)$ no masculino. Os indivíduos de sexo desconhecido apresentam uma diferença mais notória

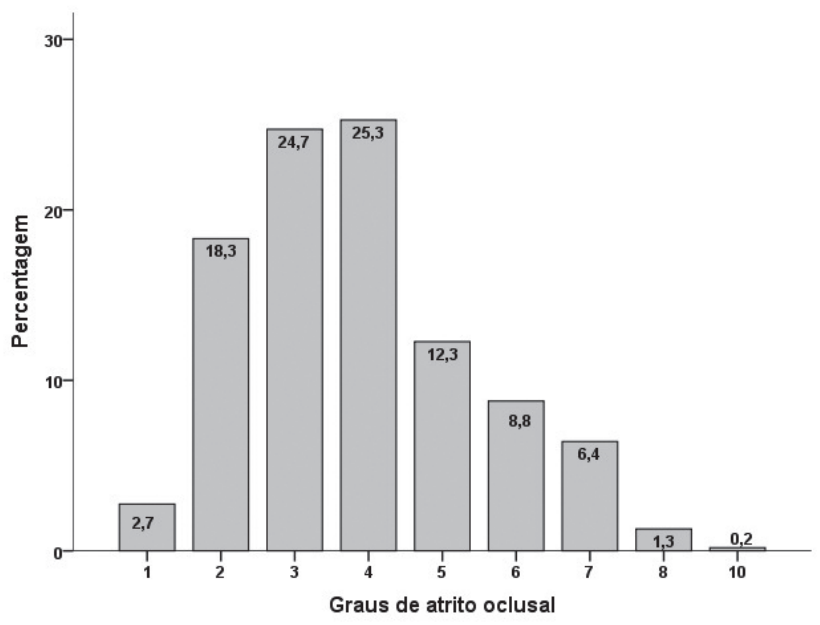

Figura 1. Percentagem de dentes afetados por grau de desgaste da amostra de SJA.

Tabela 2. Frequência dos graus de desgaste oclusal, por sexo, na amostra de SJA.

\begin{tabular}{lcccc}
\hline Graus de Desgaste & $\begin{array}{c}\text { Sexo Masculino } \\
(\% / \mathbf{n})\end{array}$ & $\begin{array}{c}\text { Sexo Feminino } \\
(\% / \mathbf{n})\end{array}$ & $\begin{array}{c}\text { Sexo } \\
\text { Indeterminado } \\
(\% / \mathbf{n})\end{array}$ & $\begin{array}{c}\text { Total } \\
(\% / \mathbf{n})\end{array}$ \\
\hline $\mathbf{1}$ & $1,5(5)$ & $4,6(7)$ & $4,9(3)$ & $2,7(15)$ \\
$\mathbf{2}$ & $11,8(39)$ & $\mathbf{3 5 , 7}(55)$ & $9,8(6)$ & $18,3(100)$ \\
$\mathbf{3}$ & $27,2(90)$ & $24(37)$ & $13,1(8)$ & $24,7(135)$ \\
$\mathbf{4}$ & $\mathbf{2 9 , 6 ( 9 8 )}$ & $16,9(26)$ & $22,9(14)$ & $\mathbf{2 5 , 3}(138)$ \\
$\mathbf{5}$ & $12,4(41)$ & $7,1(11)$ & $\mathbf{2 4 , 6 ( 1 5 )}$ & $12,3(67)$ \\
$\mathbf{6}$ & $10(33)$ & $3,9(6)$ & $14,8(9)$ & $8,8(48)$ \\
$\mathbf{7}$ & $6,3(21)$ & $6,5(10)$ & $6,6(4)$ & $6,4(35)$ \\
$\mathbf{8}$ & $0,9(3)$ & $1,3(2)$ & $3,3(2)$ & $1,3(7)$ \\
Dentes fraturados & $0,3(1)$ & $0(0)$ & $0(0)$ & $0,2(1)$ \\
com desgaste & $100(331)$ & $100(154)$ & $100(61)$ & $100(546)$ \\
\hline Total (\%/n) & & & &
\end{tabular}


em relação ao sexo feminino, já que o grau mais expressivo dos primeiros é o grau $5(24,6, n=15)$, ainda que com uma percentagem muito próxima do grau $4(22,9 \%, n=14)$. Há poucos casos de grau $1(n=15)$, representando apenas 2,7\% de todas as superfícies oclusais. No conjunto, o desgaste concentra-se nos graus medianos. As diferenças dos graus de desgaste por sexo foram significativas $\left(X^{2}=72,625\right.$, g.l. $\left.=16, p=0,000\right)$.

As médias de desgaste nos dentes superiores $(3,87 \pm 1,61, n=201)$ e inferiores $(3,85 \pm 1,58, n=345)$ são idênticas. A similitude da distribuição do desgaste dentário pelos maxilares foi comprovada estatisticamente $\left(X^{2}=16,992\right.$, g.l. $=9$, $p=0,049)$. Os dentes do lado direito apresentam um desgaste ligeiramente superior, com média de 3,91 ( \pm 1,62, $n=269$ ), aos do lado esquerdo, que tem uma média de 3,80 ( $\pm 1,56, \mathrm{n}=277)$. Estas diferenças não são significativas $\left(X^{2}=9,105\right.$, g.l. $\left.=8, p=0,334\right)$.

Observando as percentagens expressas na Figura 2, verifica-se que os graus 3 e 4 continuam a ser os que mais se destacam, mesmo quando se observam os dados por quadrante, exceto no maxilar superior esquerdo, em que o grau 2 tem maior expressão do que o 3.

Tendo em conta todos os tipos de dentes, aquele que apresenta um valor médio mais elevado é o primeiro molar $(4,57 \pm 1,27, n=67)$, seguido de muito perto pelo incisivo central $(4,23 \pm 1,56$, $n=53)$. Os valores médios mais baixos são

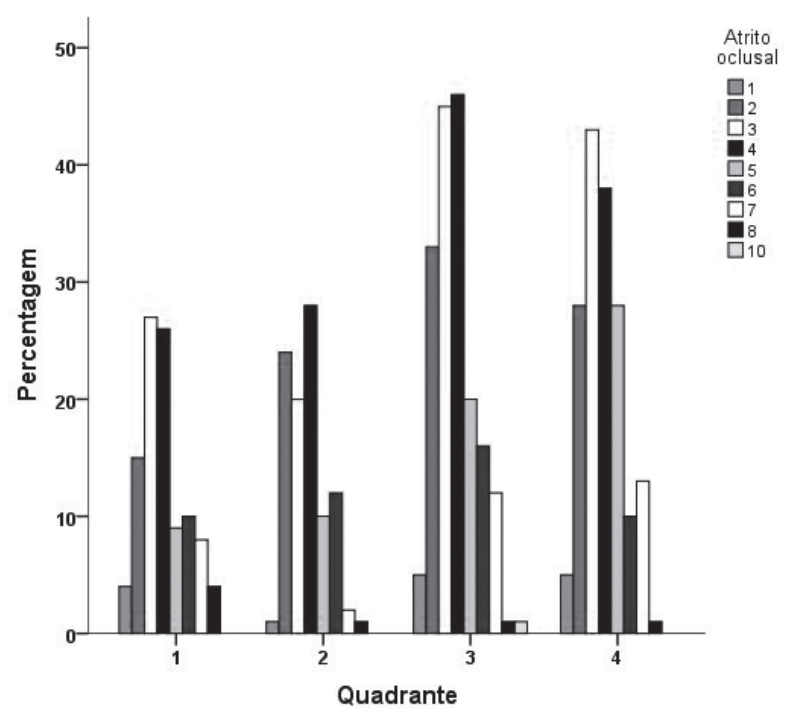

Figura 2. Distribuição do desgaste oclusal observado por grau e quadrante dentário (\%) na amostra de SJA. 
os do terceiro molar $(3,53 \pm 1,73, \mathrm{n}=58)$ e do primeiro pré-molar $(3,54 \pm 1,66$, $n=80)$. Os valores intermédios pertencem ao segundo molar $(4,07 \pm 1,33, n=73)$, canino $(3,83 \pm 1,48, n=77)$, segundo prémolar $(3,63 \pm 1,62, n=78)$ e incisivo lateral $(3,55 \pm 1,41, n=60)$.

Como se pode verificar na Figura 3, o desgaste não se manifesta do mesmo modo em todos os dentes. Podemos notar que o grau 1 está presente em todos os dentes exceto no primeiro molar. O grau 8 é mais notório nos caninos e segundos molares, sendo estes os únicos dentes que, de um modo expressivo, apresentam classificações que abrangem todos os graus.

As médias de desgaste são bastante diferentes quando avançamos nas classes etárias. Os indivíduos adultos jovens têm uma média de desgaste de 2,61 ( $\pm 0,94, n=116)$, ou seja, um desgaste moderado apenas com pequenas exposições de dentina. Aqueles que integram a classe dos adultos apresentam uma média conjunta de $4,15( \pm 1,57, n=332)$ que se caracteriza por áreas de exposição de dentina coalescentes nos molares e pré-molares e de anéis de esmalte que delimitam uma grande área de exposição de dentina, nos caninos e incisivos. Um valor ligeiramente superior, mas ainda dentro do mesmo grau, é registado para os adultos idosos (4,33 $\pm 1,52, n=98)$. Há assim uma evolução gradual no grau médio de desgaste oclusal ao longo da vida.

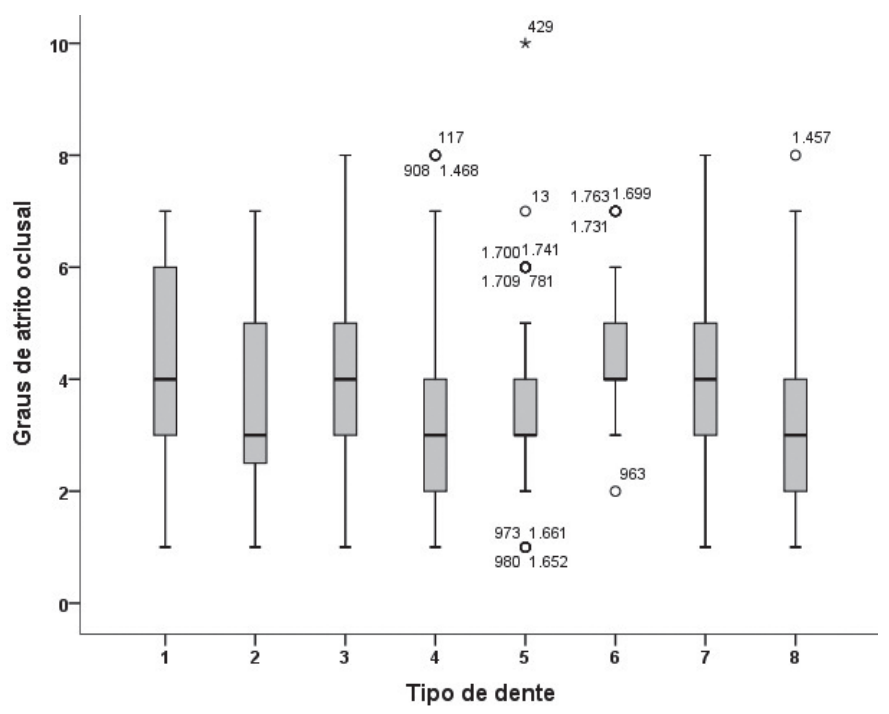

Figura 3. Intervalos de distribuição e média dos graus de desgaste oclusal pelos tipos dentários na amostra de SJA. 
Se se observar a Figura 4, é ainda mais evidente esta evolução, já que nos mais jovens o grau máximo de desgaste registado é essencialmente o 4 e o menor é o 1. É, deste modo, um intervalo de classificação bem menor do que o observado para o grupo intermédio, que abrange todos os graus. Quando se avança para a idade mais tardia, o que se nota é uma ausência dos graus mais leves de desgaste dentário.

\section{Atrito aproximal}

Foram consideradas para o estudo do atrito aproximal 524 facetas mesiais e 478 facetas distais. Esta diferença no número das facetas disponíveis para estudo deve- se ao facto de a faceta distal do terceiro molar não ser alvo de desgaste.

A média de atrito aproximal para as facetas mesiais é de $1,38( \pm 0,72, n=524)$, com 53,2\% ( $n=279)$ dos dentes a exibirem grau 1 , seguindo-se o grau $2 \mathrm{em}$ $37,2 \%(n=195)$. Os três primeiros graus contemplam 97,3\% das peças analisadas (Figura 5). Algo semelhante se passa com o desgaste das facetas distais, em que a média de desgaste é de $1,3( \pm 0,75$, $n=478$ ), resultado explicado pelos $53,6 \%$ $(n=256)$ dos dentes que exibem grau 1 . O segundo grau de atrito aproximal mais frequente é o grau $2(34,3 \%, n=164)$. Os três primeiros graus de desgaste aproximal das facetas distais contemplam 96\% dos dentes observados (Figura 6).

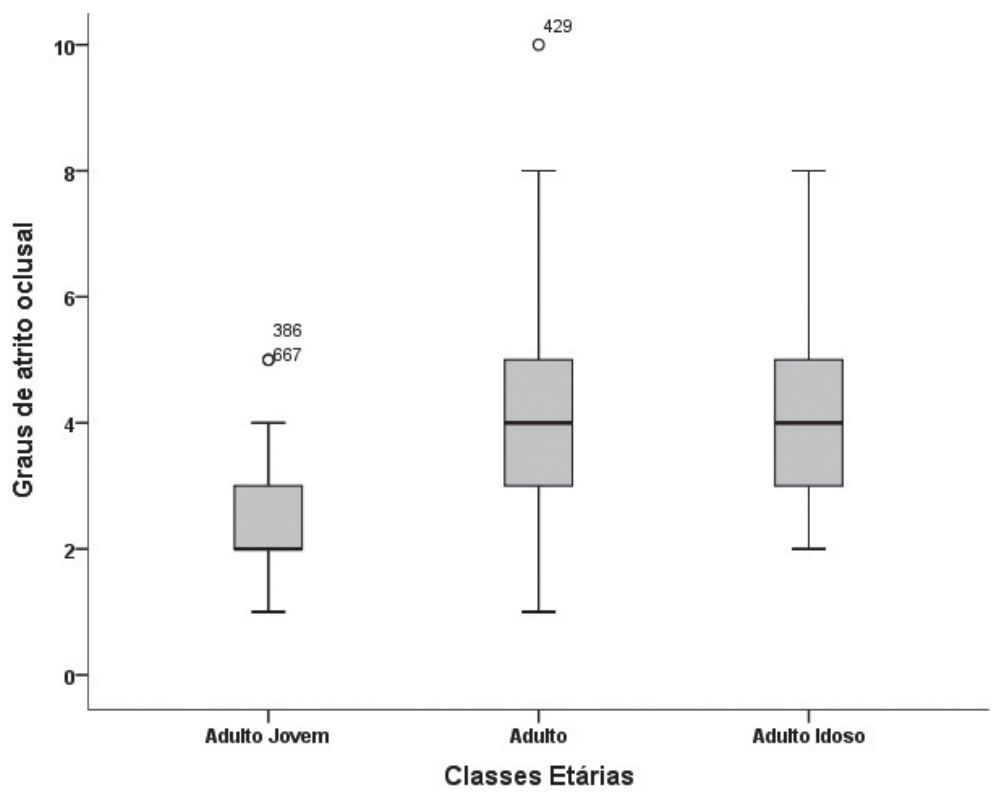

Figura 4. Intervalos de distribuição e média dos graus de atrito oclusal pelas classes etárias da amostra de SJA. 


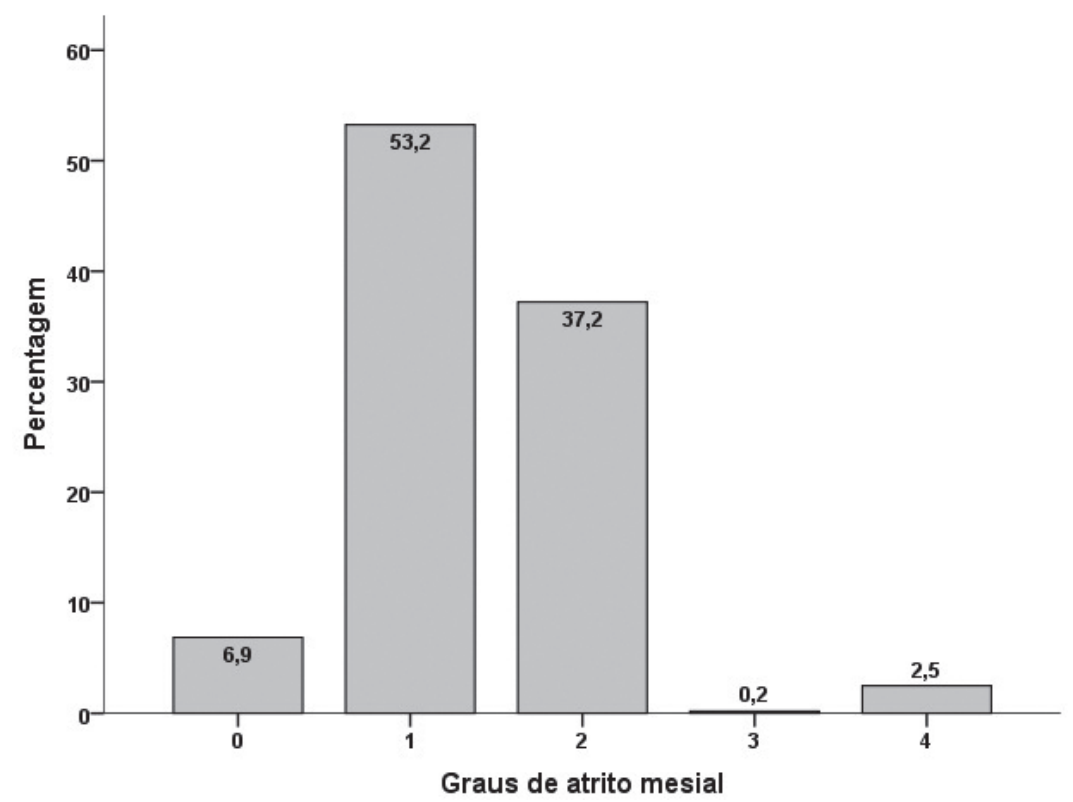

Figura 5. Distribuição do atrito mesial observado, por grau (\%), na amostra de SJA.

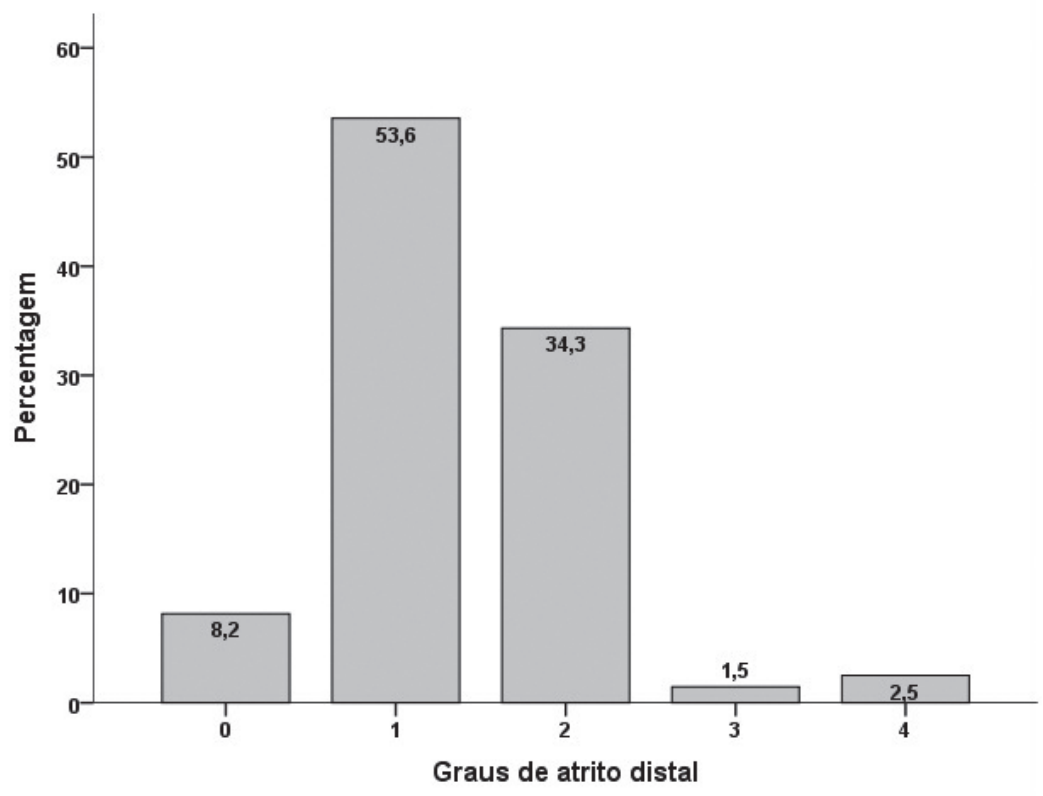

Figura 6. Distribuição do atrito distal observado, por grau (\%), na amostra de SJA. 
$\mathrm{Na}$ distribuição do atrito mesial por sexo (Figura 7), notam-se mais dentes do sexo masculino com atrito de grau 1 (36,1\%) e 2 (21,1\%). As peças dentárias femininas não exibem discrepância nestes dois graus de atrito $(11,7 \%)$. Apenas no grau 0 os indivíduos do sexo feminino exibem maior quantidade de peças dentárias (3,3\%). Os graus 3 e 4 são muito residuais. Os indivíduos de sexo indeterminado exibem ligeiramente mais elementos classificados com grau 1, seguindo-se os com grau 2. As diferenças do atrito mesial no que concerne aos sexos são significativas ( $X^{2}=16,198$, g.l. $=8, p=0,040$ ).

$\mathrm{O}$ atrito das facetas distais (Figura 8) assemelha-se muito com o das facetas mesiais. Os graus 3 e 4 são vestigiais em ambos os sexos. O grau 0 tem maior presença no sexo feminino e os graus 1 e 2 no sexo masculino. $O$ resultado nos indivíduos de sexo indeterminado nas superfícies distais é em tudo semelhante ao observado para as superfícies mesiais. Tal como no atrito mesial, também aqui as diferenças entre os sexos são significativas $\left(X^{2}=23,637\right.$, g.l. $\left.=8, p=0,003\right)$.

Como se pode observar na Tabela 3, a distribuição do atrito aproximal pelas superfícies distais e mesiais comporta-se de modo semelhante no que diz respeito aos maxilares. Estes apresentam médias de desgaste similares, $1,37( \pm 0,79, \mathrm{n}=189)$ para o mesial no maxilar superior e 1,39 $( \pm 0,68$,

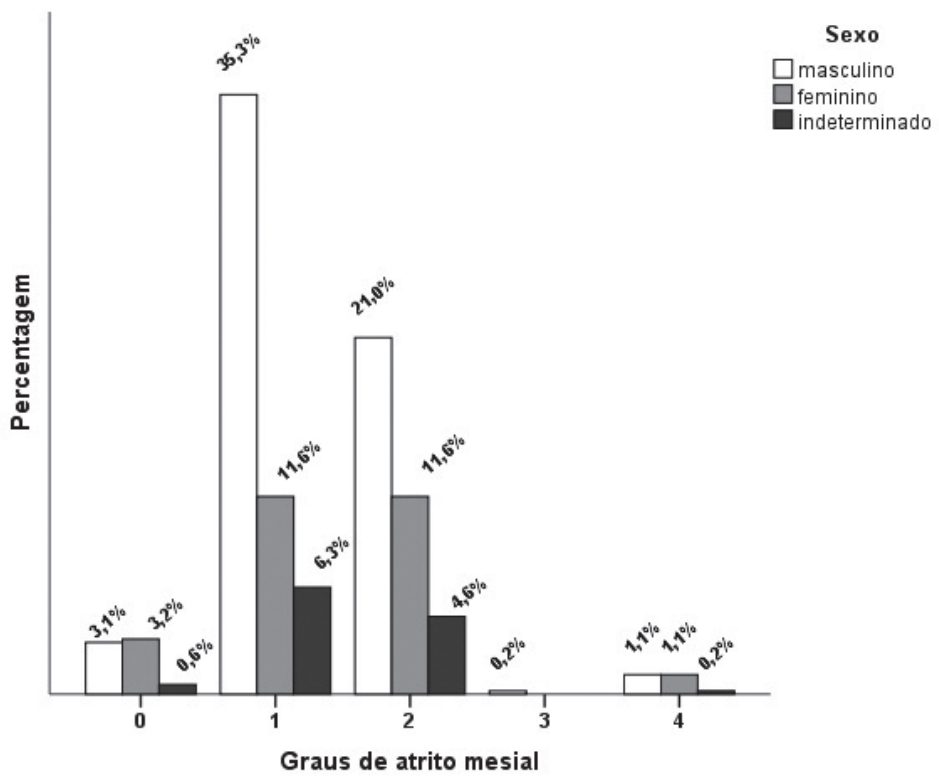

Figura 7. Distribuição do atrito mesial observado, por grau e sexo (\%), na amostra de SJA. 
$\mathrm{n}=333$ ) para o inferior. No caso do desgaste distal há uma diferença mais pronunciada entre os dois maxilares, com o superior a exibir uma média de desgaste de $1,46( \pm 0,75, n=177)$ e o inferior de 1,31 $( \pm 0,75, n=301)$. A maior diferença será a ausência do grau 3 de atrito mesial no maxilar superior, ainda que no inferior a sua presença também seja residual.

No atrito mesial, o comportamento e padrão de distribuição pelos vários graus é semelhante em ambos os maxilares, exceto o grau 3 que é mais expressivo no maxilar superior do que o grau 4, enquanto no maxilar inferior ocorre

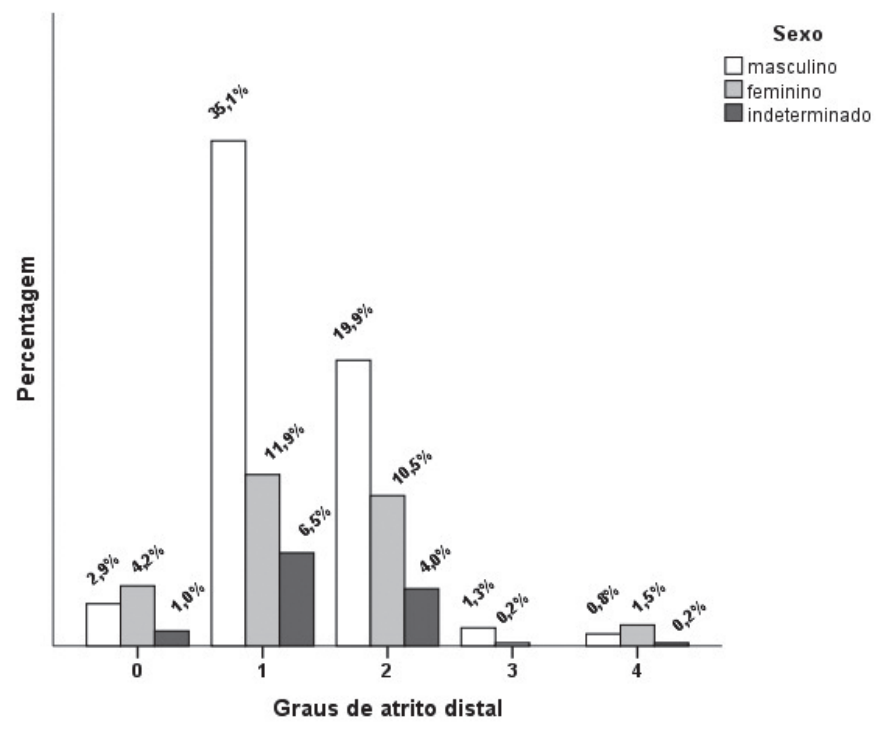

Figura 8. Distribuição do atrito distal observado, por grau (\%), na amostra de SJA.

Tabela 3. Graus de desgaste distal e mesial, por maxilar, na amostra de SJA.

\begin{tabular}{lccc}
\hline & Grau & Maxilar Inferior (\%) & Maxilar Superior (\%) \\
\hline \multirow{4}{*}{ Atrito Mesial } & 0 & 4,8 & 10,4 \\
& 1 & $\mathbf{5 5 , 9}$ & $\mathbf{4 8 , 7}$ \\
& 2 & 36,9 & 37,7 \\
& 3 & 0,3 & 0 \\
Atrito Distal & 4 & 2,1 & 3,2 \\
\hline & 0 & 9,3 & 6,2 \\
& 1 & $\mathbf{5 6 , 1}$ & $\mathbf{4 9 , 1}$ \\
& 3 & 31,2 & 39,6 \\
& 4 & 0,7 & 2,8 \\
\hline
\end{tabular}


exatamente o oposto. As diferenças nas manifestações de atrito distal $\left(X^{2}=8,191\right.$, g.l. $=4, p=0,085)$ e mesial $\left(X^{2}=7,964\right.$, g.l. $=4, p=0,093)$ em cada maxilar são significativas.

Ao observar as Figuras 9 e 10, relativas à distribuição pela lateralidade dos graus de atrito aproximal pelas superfícies mesiais e distais, não se nota uma discrepância muito relevante nos valores, com o atrito mesial esquerdo $(1,38 \pm 0,67$, $\mathrm{n}=267)$ a ter essencialmente o mesmo valor que o direito $(1,39 \pm 0,77, n=257)$. No atrito distal não existem grandes diferenças entre a média do atrito direito $(1,37 \pm 0,77, n=237)$ e esquerdo $(1,36 \pm 0,74, n=241)$ (Figura 10). Há, no entanto, que realçar alguns aspetos. O grau 0 está mais presente no lado direito no caso do atrito mesial e no esquerdo no distal. Já no grau 1 há um equilíbrio entre ambos os lados para o atrito distal, e um maior atrito mesial no lado esquerdo. Os graus 2 e 3 manifestamse mais no lado esquerdo e o 4 no direito. Esta tendência é observada nos dois tipos de desgaste. As diferenças no que concerne à distribuição do padrão de desgaste por cada lado da cavidade bucal, tanto no atrito mesial $\left(X^{2}=3,974\right.$, g.l. $=4, p=0,409)$ como no distal $\left(X^{2}=0,566\right.$, g.l. $\left.=4, p=0,967\right)$, não são significativas.

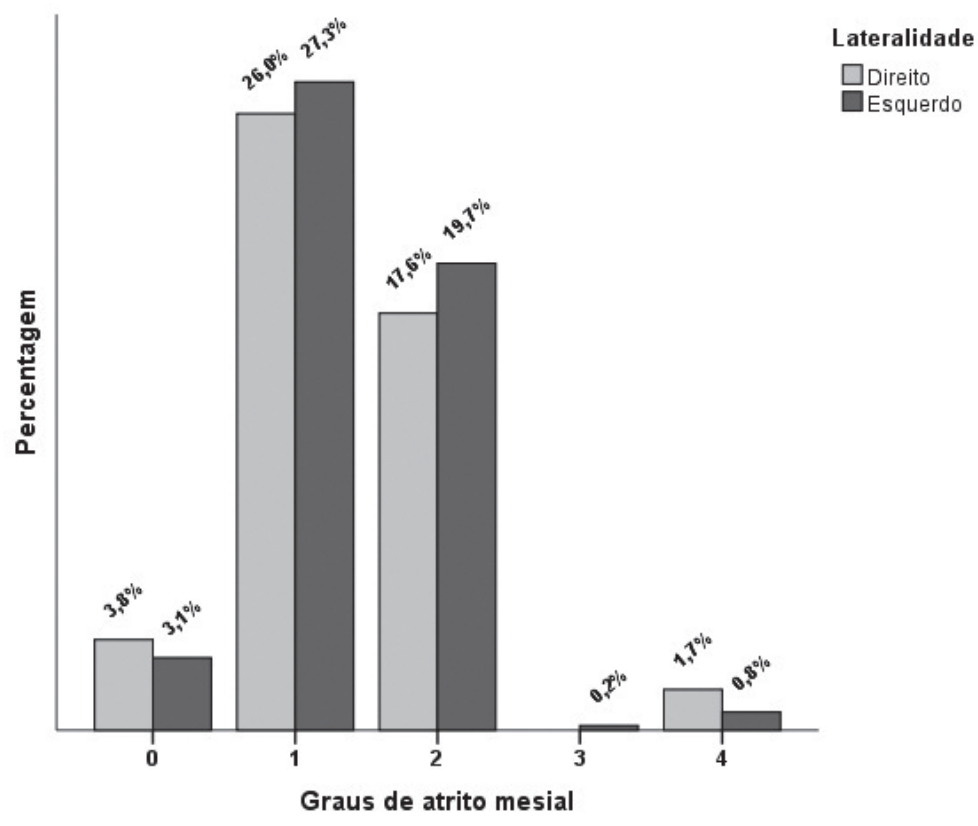

Figura 9. Distribuição do atrito mesial por grau e lateralidade, na amostra de SJA 


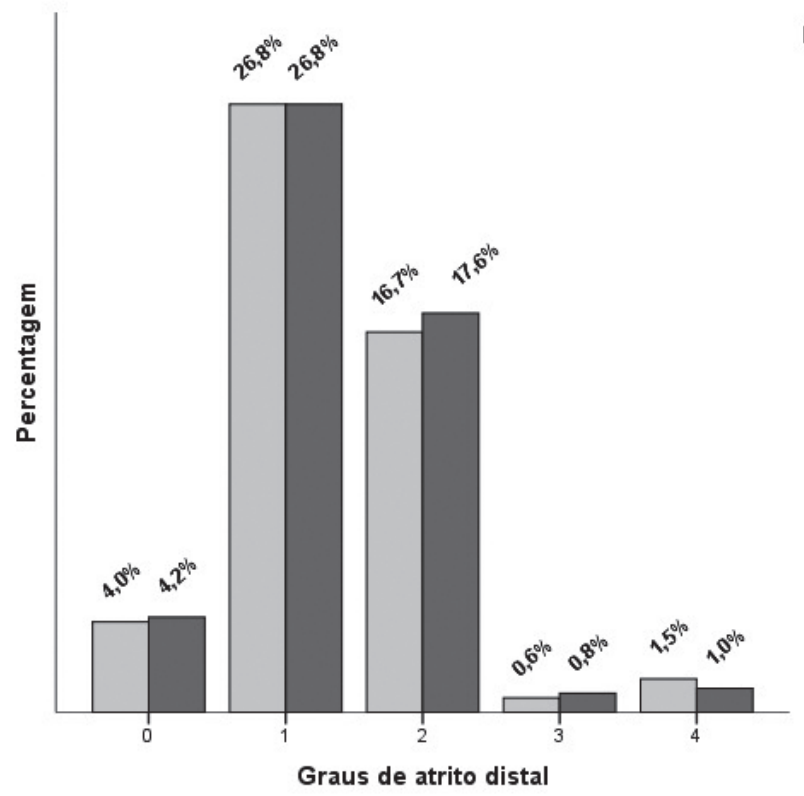

Lateralidade

$\square$ Direito

$\square$ Esquerdo

Figura 10. Distribuição do atrito distal por grau e lateralidade, na amostra de SJA.

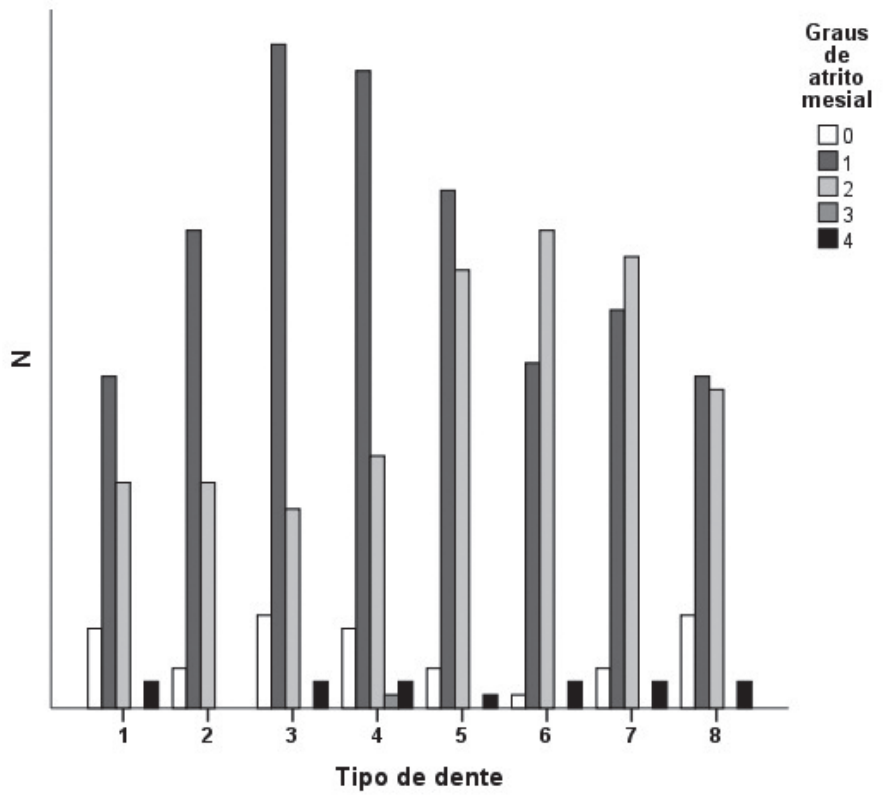

Figura 11. Distribuição do atrito mesial por grau e tipo de dente, na amostra de SJA. 
O desgaste distal e mesial não são exatamente simétricos no que diz respeito ao tipo de dente (Figuras 11 e 12). O grau 0, que se manifesta em todas as facetas aproximais de todos os tipos dentários observados, está muito mais presente nas facetas distais do segundo molar do que nas mesiais havendo uma explicação simples para o fenómeno: o terceiro molar que frequentemente não erupcionou, não pôde deixar marcas de desgaste. Como já referido anteriormente, o grau 1 é o mais expressivo, no entanto, quando se observa o atrito aproximal por tipo de dente, conclui-se que isso não acontece em todos os tipos dentários. Nas facetas mesiais dos primeiros e segundos molares e nas distais dos segundos prémolares e primeiros molares, o grau mais expressivo é o grau 2. É interessante notar que o segundo pré-molar tem a sua superfície distal em contacto com a mesial do primeiro molar e este tem a sua superfície distal em contacto com a mesial do segundo molar, estando por isso estes graus de desgaste de acordo com a sua localização, refletindo de facto um aumento do atrito nesta zona. $O$ atrito de grau 3 apenas se registou nas facetas mesiais do primeiro pré-molar. Nas facetas distais é mais frequente ocorrer em todos os tipos da dentição anterior e também no segundo pré-

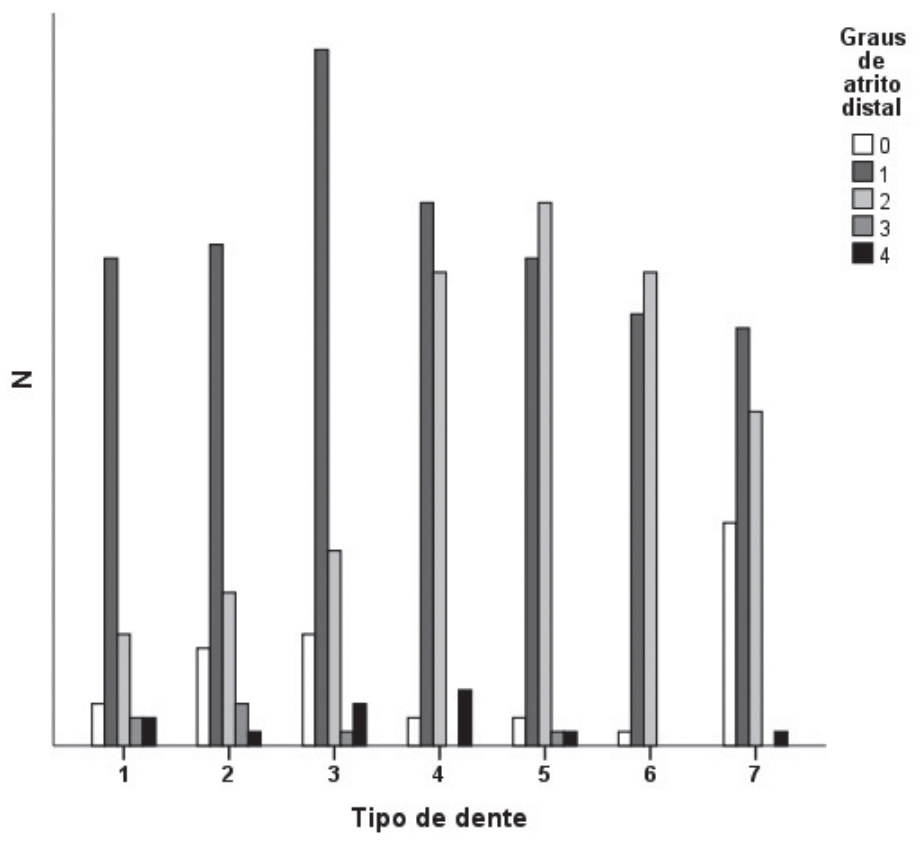

Figura 12. Distribuição do atrito distal por grau e tipo de dente, na amostra de SJA. 
molar. Curiosamente não ocorre no primeiro pré-molar. $\mathrm{O}$ grau 4 de atrito aproximal está presente em todas as facetas aproximais exceto nas mesiais dos incisivos laterais e nas distais dos primeiros molares.

Tanto as facetas aproximais mesiais como as distais nos adultos jovens não apresentam um grau de atrito maior do que 2. No atrito distal, os adultos jovens têm uma maior quantidade de dentes com grau 0 (sem desgaste) do que as outras classes etárias mais velhas. Os graus 1 e 2 têm a maior expressão e os restantes são residuais. Com o avançar da idade, o grau 1 destaca-se, mas os valores dos graus 3 (este apenas presente nos adultos) e 4 sobem ligeiramente, embora nunca alcançando grande expressão.

No atrito mesial, os adultos jovens, ao contrário do observado para o desgaste distal, exibem um maior desgaste de grau 2. Nos restantes graus e classes, o comportamento é semelhante ao observado para o desgaste mesial (Figuras 13 e 14).

\section{Discussão}

As observações revelaram uma média de desgaste oclusal de 3,86 $( \pm 1,59)$, um desgaste moderado com remoção do esmalte na zona das cúspides/ zona incisal e alguma exposição da dentina. É interessante comparar com os vestígios osteológicos medievais de soldados ingleses da Guerra das Rosas, que apresentam um desgaste severo $(5,0)$, embora alguns indivíduos idosos demonstrem desgaste até ao osso maxilar (Holst e Coughlan, 2000). Comparando os nossos resultados com

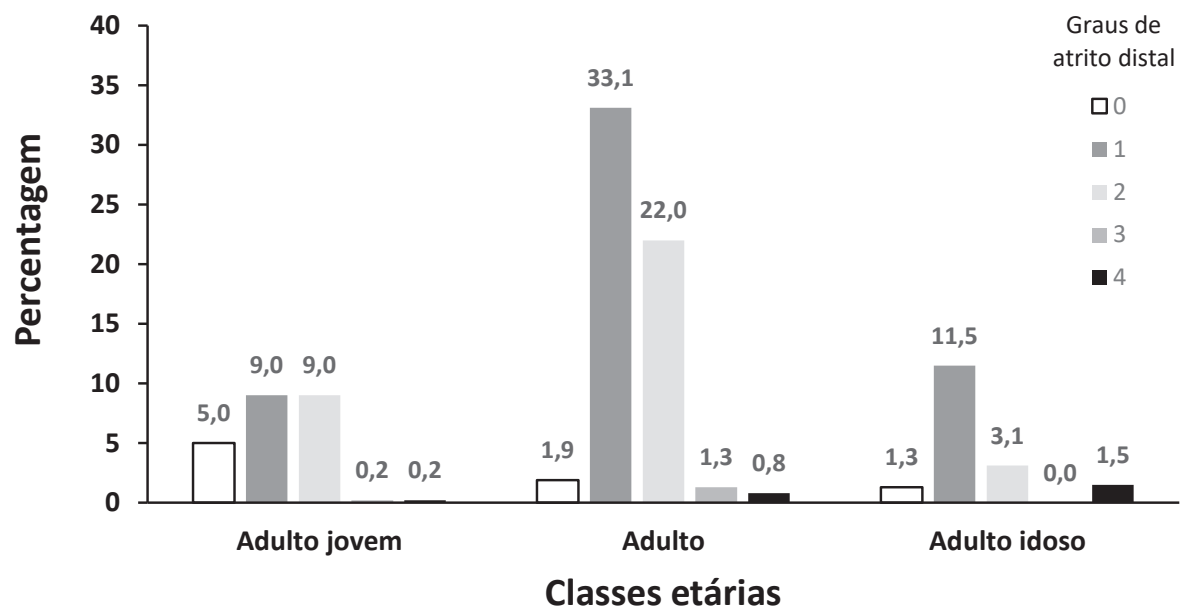

Figura 13. Distribuição do atrito distal por grau e classe etária, na amostra de SJA. 


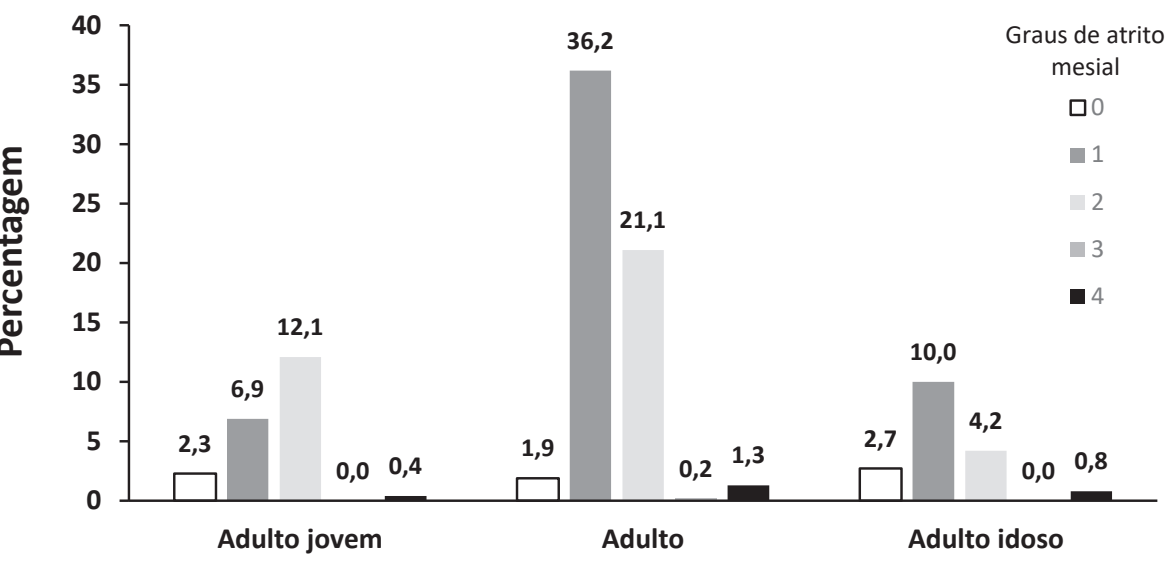

\section{Classes etárias}

Figura 14. Distribuição do atrito mesial por grau e classe etária, na amostra de SJA.

os da população pré-histórica das grutas artificiais de São Pedro do Estoril, datadas do Neolítico Final/Calcolítico, notamos alguma semelhança na média (desgaste moderado). Para tempos mais recentes, já após a Revolução Industrial, Wasterlain (2006) registou uma média de 2,6 $( \pm 1,2)$ que caracteriza um desgaste suave. A autora considera que o desgaste oclusal pouco expressivo se deve à consistência da comida, que seria macia, processada e com poucos elementos abrasivos. A dieta alicerçar-se-ia no consumo de pão com cereal bem moído, peixe bem lavado das areias e bem preparado antes do seu consumo (Wasterlain, 2006; Kiple, 2008; Almeida, 2010).

Os graus mais frequentes são o $4 \mathrm{e}$ o 3, sendo o 1 o que menos ocorre. Foi identificado, num indivíduo adulto do sexo masculino, um dente partido em vida — segundo pré-molar —, exibindo uma faceta de desgaste $(0,2 \%)$. Este tipo de desgaste foi também registado por Wasterlain (2006), que o identificou em 0,4\% do material, parecendo ser uma situação relativamente rara tanto numa época como na outra.

Araújo (1996) refere que uma marcada diferença no desgaste oclusal a favor da dentição anterior em relação à posterior pode sinalizar uma dieta com uma certa quantidade de vegetais ou/e o uso dos dentes anteriores em atividades culturais. Este não nos parece ser o caso da presente amostra - embora tenha sido detetado o uso dos dentes em atividades extramastigação - , já que os graus de maior e menor desgaste se distribuem por ambos os sectores das dentições. Os dados recolhidos vão ao encontro do anunciado por Cunha (1994) quando refere como causa o cereal pouco moído (que, quando moído, era em moinho de 
pedra) integrado na farinha de que era feito o pão consumido diariamente na época medieval (Leek, 1972). Também o peixe, frequente numa cidade ribeirinha como Coimbra, poderia ter contribuído para o desgaste verificado caso fosse mal lavado, transportando consigo elementos abrasivos, como areia. Cunha (1994) nota ainda a necessidade de mastigação vigorosa para consumir carnes secas, modo de conserva deste tipo de alimento (Kiple, 2008). O desgaste tende a assumir mais severidade quanto mais abrasiva for a dieta (Leek, 1972). Assim, dada a grande dependência de pão, a moagem do cereal - mais grosseira - contribuiria, em grande parte, para o grau de desgaste (Powell, 1985).

As médias registadas para os dois sexos diferem um pouco, com o masculino a exibir maior desgaste $(4,02 \pm 1,49)$ do que o feminino $(3,31 \pm 1,62)$. Wasterlain (2006) encontrou vários dentes com desgaste idêntico no sexo masculino e feminino mas, ainda assim, de um modo geral registou graus mais elevados no sexo masculino e graus de desgaste mais suave no feminino. Também Gama (2003), em material de Eira Pedrinha (Neolítico Final/Calcolítico), encontrou um maior desgaste nos dentes do sexo masculino. Estas diferenças podem ser justificadas com fatores biológicos, já que o maxilar dos homens é mais robusto, fazendo maior pressão sobre os dentes oponentes aquando da mastigação ou em situações de stresse (Wasterlain, 2006). Também os fatores sociais e culturais, como a divisão sexual do trabalho ou o consumo de alimentos diferenciados, podem fornecer uma explicação (Molnar, 1971). Esta é, no entanto, uma questão que não gera consenso, variando muito de população para população. Alguns investigadores acreditam que os fatores de variabilidade podem inclusivamente não ter que ver com o sexo mas, sim, com a idade média de cada sexo presente (Wasterlain, 2006).

Quanto aos maxilares, a média de desgaste é semelhante $(3,87 \pm 1,61$ para o superior e 3,85 \pm 1,58 para o inferior), conclusão idêntica à de Cunha (1994) e Araújo (1996). Wasterlain (2006), por seu lado, notou diferenças no desgaste de ambos os maxilares, com variações por tipo de dente. No caso dos primeiros e segundos molares e dos incisivos, o desgaste foi mais acentuado na mandíbula relativamente ao maxilar. Por sua vez, os dentes pré-molares superiores apresentaram um desgaste mais marcado do que os inferiores. Apesar dos terceiros molares e dos caninos apresentarem um maior desgaste ao nível do maxilar, as diferenças não foram significativas. Mais uma vez se mostra que estas diferenças de desgaste entre maxilares variam de população para população.

No estudo da lateralidade, o lado direito $(3,91 \pm 1,62)$ possui ligeiramente mais desgaste do que o esquerdo 
$(3,80 \pm 1,56)$, diferença ainda assim pouco acentuada. Wasterlain (2006) observou que o lado esquerdo tinha um pouco mais de desgaste que o direito. A preferência por um lado, quando se mastiga, pode dever-se a vários fatores. Se atentarmos ao nível do indivíduo, pode refletir uma opção em mastigar mais sobre um lado porque se perderam dentes no outro ou se existir dor provocada por um abcesso (Cunha, 1994; Wasterlain, 2006). Nas situações referidas, os dentes conservados podem exibir desgaste mais acentuado, como se verificou em material analisado por Jesus (2012), que reconheceu um grau 7 no único dente não perdido ante mortem de um indivíduo com mais de 60 anos. Há também a probabilidade de interação entre a artrose temporomandibular e o padrão de desgaste (Cunha, 1994). No presente caso, contudo, a ocorrência de lesões periapicais revelou-se idêntica em termos de lateralidade e não foi encontrada qualquer relação entre a assimetria de desgaste dentário e a perda dentária ante mortem. A artrose temporomandibular não foi pesquisada no presente estudo, devendo ser investigada no futuro.

O tipo dentário com maior média de desgaste é o primeiro molar $(4,57 \pm 1,27)$. O valor médio mais baixo é o do terceiro molar $(3,53 \pm 1,73)$. Este material apresenta o esperado gradiente de desgaste entre o primeiro e o segundo molar e do segundo para o terceiro. Esta diferença foi observada também por Cunha (1994) para Fão, material osteológico medieval de origem rural e com ligações à atividade piscatória, e para o material proveniente da Batalha de Towton (Holst e Coughlan, 2000). Curiosamente Wasterlain (2006) não constatou este gradiente de desgaste nos molares, apresentando o primeiro molar um desgaste muito semelhante ao segundo. A autora acredita que este padrão é consequência do desgaste suave da amostra. A diferença de desgaste entre os dois tipos de incisivos pode ser explicada pelo diferente contacto oclusal dos incisivos centrais e laterais (Wasterlain, 2006).

Em termos de evolução etária, constata-se que os jovens exibem um desgaste muito mais baixo (média de $2,61 \pm 0,94$, desgaste moderado apenas com pequenas exposições de dentina) do que o grupo dos adultos $(4,15 \pm 1,57)$ e dos adultos idosos $(4,33 \pm 1,52)$. A diferença entre os dois grupos mais velhos é bem menor, ainda que se note uma progressão com a idade. O que se observa nos mais idosos é o registo de graus mais severos e a ausência dos graus mais suaves de desgaste. Em material mais recente, a ligação do desgaste à idade — mais idade, mais desgaste — também existe, embora seja mais evidente nos homens do que nas mulheres (Wasterlain, 2006). 
Tanto Cunha (1994) como Wasterlain (2006) levantam a hipótese de o desgaste mais severo de alguns dentes poder ter sido provocado por bruxismo. Este consiste no ranger ou apertar dos dentes, usualmente durante o sono, mas também inconscientemente enquanto se está acordado, de que decorre um desgaste acentuado com padrões pouco usuais que podem afetar toda a dentição ou apenas uma parte desta (Cruwys, 1989).

Para o atrito aproximal, os valores médios foram baixos (1,38 $\pm 0,72$ para o atrito mesial e 1,3 \pm 0,75 para o atrito distal) caracterizando um desgaste suave. Em ambos os locais o grau mais comum é o 1. Embora com uma média semelhante, Wasterlain registou um desgaste aproximal mais suave, já que 95\% das facetas mesiais e $93,7 \%$ das facetas distais foram categorizadas como grau 1.

O atrito mesial tem um padrão diferente em cada sexo. Nos dentes dos indivíduos do sexo masculino, o grau mais frequente é o 1. Já nas superfícies mesiais dos indivíduos do sexo feminino tanto o grau 1 como o 2 possuem os mesmos valores. Os graus mais elevados são praticamente inexistentes. $\mathrm{O}$ atrito distal espelha o observado para o atrito mesial. Wasterlain (2006) notou que, excetuando o atrito mesial do maxilar, não há diferenças entre os sexos no desgaste aproximal.

Os maxilares apresentam médias de desgaste mesial semelhantes.
No desgaste distal, há uma diferença um pouco mais pronunciada, com o maxilar superior a exibir mais desgaste $(1,46 \pm 0,75)$ do que o inferior $(1,31 \pm 0,75)$.

Em termos de lateralidade, as diferenças são poucas, independentemente de se tratar de atrito mesial ou distal. É comum que ambos os lados da arcada revelem valores semelhantes, sendo usual juntar ambas no tratamento dos resultados.

Quando se analisou a distribuição do atrito aproximal, verificou-se que este não é exatamente similar para cada tipo de dente. Os dentes posteriores estão mais envolvidos no ato de moer os alimentos, o que cria uma maior pressão nas zonas aproximais, refletindo-se em maiores graus de desgaste. Embora residuais, os graus 3 e 4 estão presentes em várias superfícies, embora não se consiga detetar um padrão.

Os jovens não apresentam mais do que grau 2 em qualquer um dos tipos de atrito aproximal. No atrito distal, a classe dos adultos jovens tem uma maior quantidade de dentes sem desgaste do que os idosos. Uma explicação é que as superfícies distais dos segundos molares podem ainda não apresentar desgaste por os terceiros não terem erupcionado. Com o avançar da idade, no atrito distal, os graus 1 e 2 continuam a ser os mais frequentes, mas os valores registados para os graus 3 e 4 - que continuam a 
ser baixos — sobem ligeiramente. Esta é também uma das constatações de Wasterlain (2006) que reconhece uma evolução mais marcada no desgaste mesial da mandíbula. O atrito mesial dos adultos jovens tem maior frequência de desgaste de grau 2 em oposição ao distal, em que é o grau 1 o que mais prevalece. No restante, é semelhante ao distal.

O método de Smith (1984) generalizou-se e é raro o trabalho que aborda a paleobiologia do esqueleto que não use esta ferramenta. Assim, considerou-se importante elencar alguns dos trabalhos desenvolvidos nos últimos anos em Portugal usando este método, de modo a tecer reflexões sobre os resultados alcançados. Esse resumo pode ser visualizado na Tabela 4.

Podemos observar que os nossos resultados não estão desenquadrados, já que na Idade Média os indivíduos tendiam a exibir um desgaste tão ou mais elevado do que os de épocas pré e proto-históricas. Em épocas posteriores, o desgaste tornou-se menor. Para interpretar este dado, temos que centrar a atenção no alimento mais consumido, 0 que na época medieval nos leva de volta ao tema do pão (Kiple, 2008; Gonçalves, 2010). Em épocas mais recuadas, o consumo cerealífero era recorrente, no entanto, a produção mais familiar, ainda que com mós manuais, poderia contribuir para um maior cuidado em não incluir partículas nas farinhas (Kiple, 2008).
Em época medieval, principalmente nas cidades, em que o pão já não era fabricado em casa mas, sim, comprado, para que este fosse acessível, teria que ser "adulterado", fosse com mistura de outros cereais ou mesmo com outras partículas (Coelho, 1989). Poderão ser estas partículas, juntamente com outros alimentos abrasivos, a estar na origem do elevado desgaste (Leek, 1972). Este poderá favorecer outras patologias, como a doença periodontal ou mesmo algumas inflamações periapicais, quando a produção de dentina secundária não é suficiente para impedir o acesso das bactérias à câmara polpar (Hillson, 2001). Por outro lado, estes níveis de desgaste podem limitar o aparecimento de cáries em fase inicial, diminuindo a sua frequência face a épocas com menos desgaste, o que se verifica, de certo modo, confrontando os dados de Carvalho (2013) e Wasterlain (2006).

Embora a metodologia de Smith (1984) seja comum e fácil de aplicar, há uma grande discrepância na apresentação dos resultados de cada investigação. A falta de uma média (preferencialmente com desvio padrão), de percentagens ou de uniformidade nos campos comparativos (lateralidade, maxilar, dentes com mais e menos desgaste, por sexo e por classe etária) impossibilita uma confrontação aprofundada. Muitas vezes não são produzidas percentagens ou são-no de 
Tabela 4. Desgaste oclusal em populações portuguesas segundo o método de Smith (1984).

\begin{tabular}{|c|c|c|c|c|c|}
\hline Série osteológica & Cronologia & Média & $\begin{array}{l}\text { Graus mais } \\
\text { frequentes }\end{array}$ & $\begin{array}{c}\text { Avaliação } \\
\text { qualitativa } \\
\text { (pelos autores) }\end{array}$ & $\begin{array}{c}\text { Referência } \\
\text { bibliográfica }\end{array}$ \\
\hline $\begin{array}{l}\text { Cabeço da Arruda } 1 \text { (Torres } \\
\text { Vedras) }\end{array}$ & $\begin{array}{l}\text { Neolítico/ } \\
\text { Calcolítico }\end{array}$ & $3,89 \pm 1,18$ & & & Silva, 2012 \\
\hline $\begin{array}{l}\text { Cova da Moura (Torres } \\
\text { Vedras) }\end{array}$ & $\begin{array}{l}\text { Neolítico/ } \\
\text { Calcolítico }\end{array}$ & $3,65 \pm 1,75$ & & & Silva, 2012 \\
\hline $\begin{array}{l}\text { Dólmen junto à estrada de } \\
\text { Ansião (Leiria) }\end{array}$ & $\begin{array}{l}\text { Neolítico / } \\
\text { Calcolítico }\end{array}$ & $4 \pm 1,92$ & & & Silva, 2012 \\
\hline Paimogo (Lourinhã) & $\begin{array}{l}\text { Neolítico/ } \\
\text { Calcolítico }\end{array}$ & $3,51 \pm 1,67$ & & & Silva, 2012 \\
\hline $\begin{array}{l}\text { Gruta artificial de São } \\
\text { Paulo (Setúbal) }\end{array}$ & $\begin{array}{l}\text { Neolítico/ } \\
\text { Calcolítico }\end{array}$ & $3,86 \pm 1,70$ & & & Silva, 2012 \\
\hline $\begin{array}{l}\text { Necrópole da Serra da } \\
\text { Roupa (Bombarral) }\end{array}$ & $\begin{array}{l}\text { Neolítico/ } \\
\text { Calcolítico }\end{array}$ & $3,10 \pm 1,55$ & & & Silva, 2012 \\
\hline Torre Velha 3 (Serpa) & $\begin{array}{l}\text { Bronze Médio } \\
\text { do Sudoeste }\end{array}$ & $3,65 \pm 1,65$ & & & Fidalgo, 2014 \\
\hline Casas Velhas (Grândola) & Idade do Bronze & 2,8 & 1 & & Gil, 2014 \\
\hline Monte da Cabida 3 (Évora) & Idade do Bronze & & & & Gil, 2014 \\
\hline $\begin{array}{l}\text { Castro de Avelãs (Bra- } \\
\text { gança) }\end{array}$ & $\begin{array}{l}\text { Alta Idade Média } \\
\text { (Séc. VII/XIII) }\end{array}$ & & 3 e 4 & & Brito, 2013 \\
\hline $\begin{array}{l}\text { Basílica Paleocristã de } \\
\text { Conimbriga }\end{array}$ & $\begin{array}{l}\text { Alta Idade Média } \\
\text { (Séc. IX/X) }\end{array}$ & & 2 & & Ventura, 2010 \\
\hline $\begin{array}{l}\text { Alcáçova do Castelo de } \\
\text { Mértola }\end{array}$ & $\begin{array}{c}\text { Medieval } \\
\text { (Séc. XIV/XVI) }\end{array}$ & & 3,4 e 5 & médio & Leandro, 2011 \\
\hline $\begin{array}{l}\text { Santa Maria dos Olivais } \\
\text { (Tomar) }\end{array}$ & $\begin{array}{l}\text { Medieval/ } \\
\text { Moderna }\end{array}$ & & 4 & médio & $\begin{array}{c}\text { Gonçalves, } \\
2011\end{array}$ \\
\hline Sé Velha de Coimbra & $\begin{array}{l}\text { Medieval/ } \\
\text { Moderna }\end{array}$ & & 2 & suave & Teixeira, 2007 \\
\hline $\begin{array}{l}\text { São João de Almedina } \\
\text { (Coimbra) }\end{array}$ & $\begin{array}{c}\text { Medieval } \\
\text { (séc. XII-XVI) }\end{array}$ & $3,86 \pm 1,59$ & 3 e 4 & médio & Carvalho, 2013 \\
\hline $\begin{array}{l}\text { Igreja de São Bartolomeu } \\
\text { (Coimbra) }\end{array}$ & $\begin{array}{c}\text { Medieval/ } \\
\text { Moderna } \\
\text { (séc. XII-XVII) }\end{array}$ & & 4 & & Costa, 2010 \\
\hline $\begin{array}{l}\text { Rua dos Barcos (Ribeira de } \\
\text { Santarém) }\end{array}$ & $\begin{array}{c}\text { Moderna } \\
\text { (Séc. XVI/XVII) }\end{array}$ & 2,78 & 2 e 3 & suave a médio & Januário, 2006 \\
\hline Convento de Santa Ana & Moderna & 2,9 & 1 e 2 & & Silva, 2007 \\
\hline $\begin{array}{l}\text { Colégio de Santo Antão-o- } \\
\text { Novo (Lisboa) }\end{array}$ & $\begin{array}{c}\text { Moderna } \\
\text { (Séc. XVI/XVIII) }\end{array}$ & & 2 & baixo & Godinho, 2008 \\
\hline $\begin{array}{l}\text { Praça do Comércio de } \\
\text { Coimbra }\end{array}$ & $\begin{array}{c}\text { Moderna/ } \\
\text { Contemporânea } \\
\text { (Séc. XV/XX) }\end{array}$ & 3,33 & 3 e 4 & médio & Ascenso, 2007 \\
\hline $\begin{array}{l}\text { Igreja de São Julião (Figuei- } \\
\text { ra da Foz) }\end{array}$ & $\begin{array}{c}\text { Moderna/ } \\
\text { Contemporânea } \\
\text { (Séc. XVII/XIX) }\end{array}$ & 2,4 & 1 & suave & Pinto, 2012 \\
\hline $\begin{array}{l}\text { Serra do Pilar (Vila Nova } \\
\text { de Gaia) }\end{array}$ & $\begin{array}{c}\text { Moderna/ } \\
\text { Contemporânea } \\
\text { (Séc. XVII/XIX) }\end{array}$ & 3,53 & & & Neves, 2007 \\
\hline $\begin{array}{l}\text { Coleções Osteológicas } \\
\text { Identificadas UC }\end{array}$ & $\begin{array}{c}\text { Contemporânea } \\
\text { (Séc. XIX/ XX) }\end{array}$ & $2,6 \pm 1,2$ & 2 & & $\begin{array}{l}\text { Wasterlain, } \\
2006\end{array}$ \\
\hline
\end{tabular}


um modo menos correto, o que também inviabiliza o confronto dos dados. Assim, torna-se essencial uma padronização não apenas no método, mas também na forma de apresentar os dados.

\section{Conclusão}

Tentou-se indagar sobre o desgaste dentário como reflexo da alimentação dos indivíduos de uma população de classe média urbana medieval.

O desgaste oclusal revelou-se moderado, refletindo uma dieta abrasiva, resultante provavelmente não apenas dos alimentos mas também do seu modo de preparação. Os homens apresentavam um desgaste mais acentuado do que as mulheres que estava relacionado com a idade. Esta relação foi visível não só com o aumento da média à medida que se ia evoluindo nas classes etárias, mas também coma diminuição dos graus mais suaves e o aumento dos mais severos. Notou-se a existência de um gradiente entre os molares, com o primeiro a apresentar o maior desgaste de todos os tipos dentários e o terceiro o menor. O desgaste oclusal foi semelhante nos dois maxilares e em ambos os lados.

O atrito aproximal mostrou-se pouco severo, denotando como pode ser diferente do registado oclusalmente. O padrão deste desgaste foi diferente em cada um dos sexos, embora a média seja semelhante. Tal como o desgaste oclusal, este também se relacionava com a idade, embora de modo menos expressivo. Quando observados por maxilar e por lateralidade, os valores foram similares, o que torna a sua expressão muito homogénea. Com a mesma alimentação e ambiente, o atrito aproximal manifesta-se de modo mais suave do que o oclusal, tendo também uma evolução de severidade mais lenta.

A confrontação com dados sobre o desgaste oriundos de outras cronologias fornece um quadro em que este será muito marcado na Idade Média e diminuirá até à época contemporânea provavelmente fruto de um maior processamento dos alimentos.

Abordou-se também o uso do método deSmith (1984), umaferramenta poderosíssima pela sua utilidade e implantação na comunidade científica. No entanto, considera-se essencial, para uma boa comparação dos resultados, que estes sejam apresentados de forma mais homogénea possível, o que implica uma leitura demográfica (sexo e idade à morte), por quadrante (lateralidade e maxilar) e por tipo de dente. É essencial, também, que sejam produzidas médias de desgaste e percentagens corretas de ocorrência. Deste modo, o estudo dos padrões de desgaste, que assim terá uma maior 
base comparativa, poder-se-á revelar ainda mais desafiante.

\section{Agradecimentos}

As autoras gostariam de agradecer ao Centro de Investigação em Antropologia e Saúde (CIAS) e aos revisores cujos comentários e sugestões permitiram melhorar a qualidade deste trabalho. A presente investigação foi financiada por fundos nacionais da FCT — Fundação para a Ciência e Tecnologia, através do projeto com a referência UID/ ANT/00283/2013.

\section{Referências bibliográficas}

Almeida, A. N. (coord.). 2010. História da vida privada em Portugal. Os nossos dias. Lisboa, Círculo de Leitores.

Araújo, M. T. G. L. 1996. Os dentes humanos das grutas artificiais de S. Pedro do Estoril: incidência de algumas lesões patológicas e estudo de desgaste numa amostra de dentes do Neolítico Final/ Calcolítico. Dissertação de Mestrado em Arqueologia, Instituto de Ciências Sociais da Universidade do Minho.

Ascenso, B. F. R. 2007. À descoberta de Coimbra antiga: análise paleobiológica de uma amostra osteológica de esqueletos e ossário provenientes da Praça do Comércio de Coimbra. Dissertação de investigação em Antropologia Biológica da licenciatura em Antropologia, Departamento de Antropologia, Faculdade de Ciências e Tecnologia, Universidade de Coimbra.

Brito, A. F. 2013. Castro de Avelãs (Bragança): análise de uma amostra populacional exumada do sítio da Torre Velha. Dissertação de Mestrado em Evolução e Biologia Humanas, Departamento de Ciências da Vida, Faculdade de Ciências e Tecnologia, Universidade de Coimbra.

Carvalho, L. 2013. Regressando a São João de Almedina (Coimbra, Portugal): estudo da patologia oral de uma população medieval urbana. Dissertação de Mestrado em Evolução e Biologia Humanas. Departamento de Ciências da Vida, Faculdade de Ciências e Tecnologia, Universidade de Coimbra.

Carvalho, P. 1998. O Forum de Aeminium. Lisboa, Ministério da Cultura.

Coelho, Maria H. C. 1989. O Baixo Mondego nos finais da Idade Média. Estudo de História Rural (2 vols.). Lisboa, Imprensa Nacional-Casa da Moeda.

Costa, I. 2010. Fragmentos das vivências em S. Bartolomeu: análise antropológica de uma série osteológica proveniente da Igreja românica de São Bartolomeu de Coimbra. Dissertação de Mestrado em Evolução e Biologia Humanas, 
Departamento de Ciências da Vida Faculdade de Ciências e Tecnologia da Universidade de Coimbra.

Cruwys, E. 1989. Tooth wear and the archaeologist: the role of human tooth wear in archaeological research. In: Roberts, C.A; Lee, F; Bintliff, J. (eds.) Burial Archaeology, current research, methods and developments. Oxford, Bar series 211: 151-166.

Cunha, A. X. 1963. Contribuição antropológica para o estudo de portugueses medievais: o espólio ósseo das sepulturas de S. João de Almedina. Contribuições para o estudo da Antropologia Portuguesa, 7(8): 176-188.

Cunha, E. 1994. Paleobiologia das populações medievais portuguesas: os casos de Fão e de S. João de Almedina. Tese de Doutoramento em Antropologia, Departamento de Antropologia, Faculdade de Ciências e Tecnologia, Universidade de Coimbra.

Fidalgo, D. F. F. 2014. Contextos funerários e estudo antropológico dos restos ósseos humanos dos hipogeus de Torre Velha 3 (São Salvador, Serpa): uma aproximação ao estudo das comunidades humanas do Bronze do sudoeste. Dissertação de Mestrado em Evolução e Biologia Humanas, Departamento de Ciências da Vida, Faculdade de Ciências e Tecnologia, Universidade de Coimbra.

Forshaw, R.J. 2009. Dental health and disease in ancient Egypt. British Dental Journal, 206: 421-424.

Gama, R. P. V. F. 2003. Ressuscitar Eira Pedrinha
Neolítica/Calcolítica: uma nova abordagem antropológica. Dissertação de Mestrado em Evolução Humana, Departamento de Antropologia, Faculdade de Ciências e Tecnologia, Universidade de Coimbra.

Gil, P. A. A. 2014. Necrópoles de Cistas na realidade do Sudoeste Peninsular durante o Il milénio a.C.: práticas funerárias e análise antropológica dos restos ósseos humanos exumados das Necrópoles de Casas Velhas e Monte da Cabida 3. Dissertação de Mestrado em Evolução e Biologia Humanas, Departamento de Ciências da Vida, Faculdade de Ciências e Tecnologia, Universidade de Coimbra.

Godinho, R. M. 2008. Vestígios de um império passado: a necrópole do Colégio de Santo Antão-o-Novo e a Lisboa dos séculos XVI-XVIII. Dissertação de Mestrado em Evolução e Biologia Humanas, Departamento de Ciências da Vida, Faculdade de Ciências e Tecnologia, Universidade de Coimbra.

Gonçalves, A. 2011. Estudo paleobiológico de uma amostra osteológica inumada em Santa Maria dos Olivais, Tomar. Dissertação de Mestrado em Evolução e Biologias Humanas, Departamento de Ciências da Vida, Faculdade de Ciências e Tecnologia, Universidade de Coimbra.

Gonçalves, I. 2010. A alimentação. In: Almeida, A. N. (coord.) História da vida privada em Portugal. Os nossos dias. Lisboa, Círculo de Leitores.

Hillson, S. 1986. Teeth. Cambridge manuals in 
Archaeology. Cambridge, Cambridge University Press.

Hillson, S. 1996. Dental Anthropology. Cambridge, Cambridge University Press. Hillson, S. 2000. Dental pathology. In: Katzenberg, M.; Saunders, S. (eds.) Biological anthropology of the human skeleton. New York, Wiley-Liss: 249-286. Hillson, S. 2001. Recording dental caries in archaeological human remains. International Journal of Osteoarchaeology, 11(4): 249-286. DOI: 10.1002/oa.538.

Hodges, D.C. 1991. Temporomandibular joint osteoarthritis in a British skeletal population. American Journal of Physical Anthropology, 85: 367-377.

Holst, M.; Coughlan, J. 2000. Dental health and disease. In: Fiorato, V.; Boyston, A.; Knusel, C. (eds.) Blood red rose: the archaeology of a mass grave from the Battle of Towton AD 1461. Oxford, Oxford Books: 77-89.

Januário, S. M. 2006. Em busca de Santarém Medieval: análise antropológica de um ossário proveniente da Necrópole Medieval da Rua dos Barcos, em Ribeira de Santarém. Dissertação de Investigação em Antropologia Biológica da Licenciatura em Antropologia, Departamento de Antropologia, Faculdade de Ciências e Tecnologia, Universidade de Coimbra.

Jesus, C. C. 2012. Museu nacional Machado de Castro: resquícios duma Coimbra Medieval. Estudo paleobiológico de uma amostra exumada da antiga igreja românica de S. João de Almedina. Dissertação de Mestrado em Evolução e Biologia Humanas. Departamento de Ciências da Vida, Faculdade de Ciências e Tecnologia, Universidade de Coimbra.

Kiple, K. F 2008. Uma história saborosa do mundo: dez milénios de globalização alimentar. Cruz Quebrada, Casa das Letras.

Leandro, I. R. R. 2011. Mértola: testemunhos de um passado medieval. Estudo paleobiológico de 30 esqueletos provenientes da Alcáçova do Castelo de Mértola. Dissertação de Mestrado em Evolução e Biologias Humanas, Departamento de Ciências da Vida, Faculdade de Ciências e Tecnologia, Universidade de Coimbra.

Leek, F. (1972). Teeth and bread in ancient Egypt. The Journal of Egyptian Archaeology, 58, 126-132.

Marquez-Grant, N. 2009. The humam remains from the church of São João and São Vicente (Bragança, Portugal). Oxford, Vessants Arqueologia i Cultura.

Molnar, S. 1971. Human tooth wear, tooth function and cultural variability. American Journal of Physical Anthropology, 34(2): 175-189. DOI: 10.1002/ajpa.1330340204.

Molnar, P. 2001. Extramasticatory dental wear reflecting habitual behavior and health in past populations. Clinical Oral Investigations, 15: 681-689.

Murphy, T. 1959. The changing pattern of 
dentine exposure in human tooth attrition. American Journal of Physical Anthropology, 17: 167-178. DOI: 10.1002/ajpa.1330170302.

Neves,M.J.2007. NecrópoledaSerrado Pilar(Vila Nova de Gaia): análise paleobiológica da série esquelética exumada. Trabalho de investigação do Major da Licenciatura em Antropologia, Departamento de Antropologia, Faculdade de Ciências e Tecnologia, Universidade de Coimbra.

Nogueira, I; Magalhães, R. R. 2008. Coimbra: das origens a finais da Idade Média. Coimbra, Câmara Municipal de Coimbra.

Pinto, R. J. S. 2012. Memórias Figueirenses: estudo paleoantropológico de um ossário exumado da lgreja Matriz de São Julião da Figueira da Foz. Dissertação de Mestrado em Evolução e Biologia Humanas, Departamento de Ciências da Vida, Faculdade de Ciências e Tecnologia, Universidade de Coimbra.

Powell, M. L. 1985. The analysis of dental wear and caries for dietary reconstruction. In: Gilbert R.I., Mielke, J.H. (eds.) The analysis of the prehistoric diets. San Diego, Academic Press: 307-338.

Roberts, C., Manchester, K. 2005. The Archaeology of disease. Gloucestershire, Sutton.

Rufino, A. I. P. 2014. Modificações dentárias intencionais e patologia oral: estudo de uma amostra de escravos africanos dos séculos XV-XVII. Dissertação de Mestrado em Evolução e Biologia Humanas, Departamento de Ciências da Vida, Faculdade de Ciências e Tecnologia, Universidade de Coimbra.

Scott, E. C. 1979. Dental wear scoring technique. American Journal of Physical Anthropology, 51: 213-218. DOI: 10.1002/ajpa.1330510208.

Silva, A. M. 2012. Antropologia funerária e paleobiologia das populações portuguesas (litorais) do Neolítico final Calcolítico. Lisboa, Fundação Calouste Gulbenkian.

Silva, A. S. B. 2007. O código dos ossos: ressuscitar o Convento de Santa Ana de Coimbra a partir dos seus remanescentes ósseos. Tese de investigação em Antropologia Biológica da licenciatura em Antropologia, Departamento de Antropologia, Faculdade de Ciências e Tecnologia, Universidade de Coimbra.

Smith, B. H. 1984. Patterns of molar wear in hunter-gathereres and agriculturalists. American Journal of Physical Anthropology, 63: 39-84. DOI: 10.1002/ ajpa.1330630107.

Teixeira, C. C. 2007. Estudo antropológico do cemitério oculto da Sé Velha de Coimbra. Tese de investigação em Antropologia Biológica da Licenciatura de Antropologia, Departamento de Antropologia, Faculdade de Ciências e Tecnologias, Universidade de Coimbra.

Ventura, A. A. L. 2010. Viver e morrer na Casa de Tancinus: estudo paleodemográfico e paleopatológico de uma amostra antropológica proveniente do sector da basílica paleocristã localizado 
no perímetro da cidade romana de Conímbriga. Dissertação de mestrado em Evolução e Biologia Humanas, Departamento de Ciências da Vida, Faculdade de Ciências e Tecnologia, Universidade de Coimbra.

Wasterlain, R. S. N. 2006. "Males" da boca: estudo da patologia oral numa amostra das colecções osteológicas identificadas do Museu Antropológico da Universidade de Coimbra (finais do séc. XIX/ inícios do séc. $X X)$. Tese de Doutoramento em Antropologia, Faculdade de Ciências e Tecnologia da Universidade de Coimbra.

Wolpoff, M. H. 1971. Interstitial wear. American Journal of Physical Anthropology, 34: 205-228. DOI: 10.1002/ajpa.1330340206. 